\title{
Impact of Drying-Grinding Sequence on Loblolly Pine Chips Preprocessing Effectiveness
}

\author{
Oluwafemi Oyedeji ${ }^{1}$ and Oladiran Fasina ${ }^{2}$ \\ ${ }^{1}$ Department of Biosystems Engineering and Soil Science, 2506 E.J. Chapman Drive, \\ University of Tennessee, Knoxville, TN (E-mail: ooyedeji@vols.utk.edu) \\ ${ }^{2}$ Department of Biosystems Engineering, 200 Corley Building, \\ Auburn University, Auburn, AL 36849 (E-mail: fasinoo@auburn.edu)
}

\section{Corresponding author}

Dr. Oladiran Fasina

Department of Biosystems Engineering

200 Corley Building,

Auburn University, Auburn, AL 36849

E-mail: fasinoo@auburn.edu

Phone: 334-844-3574 


\begin{abstract}
The high amount of energy consumed during the processing of biomass inflates the production cost of bio-fuels and bio-products. This study was therefore carried out to evaluate the influence of drying and grinding sequence on biomass energy consumption and properties (specific grinding energy requirement, specific drying energy requirement, particle size distribution, bulk density, tap density, aspect ratio, and flow index of grinds). Among the six drying-grinding sequences ((12-S, 30-S, 50-S, 30-L-12-S, 50-L-12-S, and 50-L-30-S), sequence 50-S had the lowest geometric mean diameter and sequence 30-S had the highest geometric mean diameter. Drying-grinding sequence significantly affected the bulk density and tap density of grinds. The bulk density of grinds varied from $267.1 \mathrm{~kg} / \mathrm{m}^{3}$ (sequence 12-S) to $98.0 \mathrm{~kg} / \mathrm{m}^{3}$ (sequence 50-S) while the tap density ranged from $342.6 \mathrm{~kg} / \mathrm{m}^{3}$ (sequence 12-S) to $153.7 \mathrm{~kg} / \mathrm{m}^{3}$ (sequence 50-S). This variation in the densities followed the changes the particle morphology and aspect ratio distribution. A trade-off was noted between specific grinding energy requirement and specific drying energy requirement. The grinding of samples at higher moisture content consumed higher grinding energy than the grinding of samples at lower moisture content. Moisture loss during grinding however increased as the moisture content of woodchips increased, hence resulted in lower drying energy requirements. The least specific drying energy consumption was (1581 kJ/kg d.b.) for sequence 50-S and the highest specific drying energy consumption was (3933 kJ/kg d.b.) for sequence $12-S$.
\end{abstract}

\title{
Keywords.
}

drying, grinding, hammer mill, energy, particle size.

\section{Introduction}

Fossil fuels (coal, natural gas and crude oil) are used to produce fuels, energy, chemicals and products. There is the obvious need to replace some of the consumed fossil fuels with renewable alternatives (such as biobased energy, wind, solar and geothermal) because of the limited nature of fossil fuels (Cherubini and Stromman, 2011). Secondly, greenhouse gases are released into the atmosphere during the mining, exploration and/or conversion of these fossil fuels into energy. Greenhouse gases have been linked to climate change (EPA, 2012). Biomass is the only renewable resource that can be used to directly produce the liquid transportation fuels, chemicals, and polymers currently obtained from fossil fuels (Soetaert and Vandamme, 2009; USDA, 2015). In the Southeastern United States, loblolly pine (Pinus taeda) is the most abundant biomass resources, with about 12.9 million hectares of cultivated loblolly pine plantation cultivated (Samuelson et al., 2013; Zhao et al., 2014). 
Biomass have to be dried and ground before they can be fed into the throat of biorefineries conversion plants (for fuels and products production), and into pelleting mills and combustion power plants (for power and heating applications) (Tabil et al., 2011). Biomass drying is needed because most biomass feedstocks are harvested/gathered at high moisture contents ( $50 \%$ for forest biomass and $\sim 25 \%$ for energy crops). At these high harvest moisture levels, significant loss in quality of biomass feedstocks will occur due to microbial spoilage (which is typical for biological materials) after 1 to 3 days in storage (Lin and Pan, 2015). In addition, optimum conversion efficiency is obtained when dried biomass feedstocks (i.e. $<15 \%$ ) are used in thermochemical conversion processes such as gasifiers and combustion chambers (McKendry, 2002) and in pelleting operations (Kaliyan and Morey, 2009). The size of biomass feedstocks after harvest/gathering can be up to 100 fold of the particle size that can be efficiently handled by biorefinery equipment. Grinding reduces particle size and in general changes the particle shape, bulk density, flow properties, porosity and increases rate of reaction due to increase in surface area (Bitra et al., 2009; Naimi et al., 2013). However, drying and grinding are highly energy intensive processes. For example, biomass drying can account for about $15 \%$ of the total industrial energy consumption (Chua et al., 2001). The energy consumed in the size reduction of biomass accounts for one-third of the total energy consumed in the production of bioethanol (Cadoche and Lopez, 1989). Minimizing the energy consumed during biomass drying and grinding is therefore pivotal to the viability and economic competitiveness of biomass-based fuels and products.

Energy consumption during grinding depends on the initial and final particle sizes, biomass type, moisture content, pretreatments, grinding equipment type, and grinding equipment operating variables (Kokko et al., 2012; Phanphanich and Mani, 2011). Mani et al. (2004) studied the grinding of wheat straws, barley straws, corn stover, and switchgrass using a hammer mill fitted with $3.2 \mathrm{~mm}, 1.6 \mathrm{~mm}$, or $0.8 \mathrm{~mm}$ screen sizes. As expected, the authors reported that there was a negative correlation between specific grinding energy requirement and hammer mill screen size. Furthermore, specific grinding energy consumption was significantly affected by biomass type. Switchgrass grinding consumed the highest energy of $113 \mathrm{~kJ} / \mathrm{kg}$ d.b. and $231 \mathrm{~kJ} / \mathrm{kg}$ d.b. (3.2 mm and $0.8 \mathrm{~mm}$ screen size, respectively) while corn stover grinding consumed the least specific energy consumption of $45 \mathrm{~kJ} / \mathrm{kg}$ d.b. and 140 $\mathrm{kJ} / \mathrm{g}$ d.b. (3.2 $\mathrm{mm}$ and $0.8 \mathrm{~mm}$ screen size, respectively). Soucek et al. (2003) reported that the specific grinding energy for knotweed increased from $210 \mathrm{~kJ} / \mathrm{kg}$ d.b. to $1040 \mathrm{~kJ} / \mathrm{kg}$ d.b. when the moisture content of the material increased from $9.2 \%$ to $19.7 \%$. Another study reported that the specific grinding energy for switchgrass through a $1 \mathrm{~mm}$ screen size was about $213 \mathrm{~kJ} / \mathrm{kg}$ d.b. for hammer mill and about $573 \mathrm{~kJ} / \mathrm{kg}$ d.b for knife mill (Miao et al., 2011). 
The properties of biomass and the degree of bonding of water molecules to the biomass constituents influence the amount of energy required to dry biomass (Earle, 1983; Pirasteh et al., 2014). Other factors that affect drying energy consumption include the amount of moisture removed, drying method, air temperature, and air velocity (Koyuncu et al., 2007). Even though the latent heat of evaporation of water is $2247 \mathrm{~kJ} / \mathrm{kg}$, dryers require 3400 to $5000 \mathrm{~kJ} / \mathrm{kg}$ of energy to dry wood chips because the dryers are not $100 \%$ efficient (Price, 2011).

The typical sequence is to dry biomass feedstocks after harvest/gathering and then grind the dried material partly because grinding energy generally decreases as the moisture content of biomass decreases (Mani et al., 2004; Miao et al., 2011; Soucek et al., 2003). However most of the studies involving grinding energy and moisture content have been carried out on grassy biomass at moisture contents equal or lower than 20\%. Apart from the study of Oyedeji et al. (2016), no other documented study has been carried out on energy consumption during grinding of woodchips at moisture contents between 12\% (stable storage moisture content) and 50\% (harvest moisture content for woody biomass). When grinding was carried out with a hammer mill fitted with $3.18 \mathrm{~mm}$ screen, the authors found that the specific grinding energy increased from $550 \mathrm{~kJ} / \mathrm{kg}$ d.b. to $739 \mathrm{~kJ} / \mathrm{kg}$ d.b. as moisture content increased from $30 \%$ to $50 \%$. However, when the hammer mill was fitted with $6.35 \mathrm{~mm}$ screen size, specific grinding energy reduced from $183 \mathrm{~kJ} / \mathrm{kg}$ d.b. to $137 \mathrm{~kJ} / \mathrm{kg}$ d.b. as moisture content increased from $30 \%$ to $50 \%$.

One of the limitations of grinding biomass at low moisture contents is the excessive production of dust (Dooley et al., 2013) which translates into material loss. For example, Hehar et al. (2014) showed that up to $22 \%$ (by mass) of loblolly pine can be in dust form after grinding this biomass chips through 3.19 $\mathrm{mm}$ screen and at $8 \%$ moisture content. The main hazards that can result from the presence of dust in processing plants are (1) health problems (respiratory, skin and eye effects) due to dust inhalation, and contact with eyes and skin; and (2) fire/explosion. Dust in processing plants can also cause abrasion damage to equipment, impaired visibility, unpleasant odors, material loss and community relation problems (Barbosa-Canovas et al., 2005). High-moisture grinding will therefore minimize dust generation and problems associated with presence of dust in biomass processing plants. One benefit of high moisture grinding that has not been fully explored in biomass preprocessing is partial drying of biomass due to heat generated in the grinding chamber. Ghorbani et al. (2010) reported moisture loss of about $4.10 \%$ to $9.37 \%$ during grinding of alfalfa chops. Probst et al. (2013) reported that moisture loss during grinding increased with an increase in the moisture content of corn and corncobs before grinding. There is therefore the potential that high moisture grinding can be used to pre-dry biomass 
feedstocks and therefore reduce the amount of moisture to remove in subsequent drying process hence reducing the total amount of combined energy to grind and dry biomass feedstocks.

Most biomass feedstocks are initially dried and then ground when they are being prepared for conversion into fuel, chemicals and products. However, no study has been conducted to verify the suitability of this drying-grinding sequence or to whether insertion of partial drying or partial grinding will improve energy utilization and properties of resulting biomass grinds. Therefore, the novelty of this work is to determine the appropriate drying-grinding sequence for preparing woody biomass for conversion based on energy consumption and properties of the grinds. The specific objectives were to: i) investigate the influence of the drying-grinding sequence on the energy required to grind and dry loblolly pine, and ii) quantify and compare the physical and flow properties (particle size distribution, aspect ratio, bulk density, tap density, flow index, and compressibility index) of the grinds resulting from the drying-grinding sequences.

\section{Materials and methods}

\subsection{Sample preparation}

Loblolly pine woodchips were obtained from West Fraser Mill, Opelika, Alabama. The chips were air dried to about $12 \%$ moisture content and stored indoor at Auburn University Center for Advanced Science, Innovation, and Commerce (CASIC) building until the time of use. Representative sample from the chips was prepared for proximate analysis (ash, volatile matter and energy contents - Table 1) by grinding through the $1 \mathrm{~mm}$ screen of a Wiley mill. Moisture content of samples at each stage of any sequence was measured using the ASTM standard E871-82 (ASTM, 2006) by oven drying about $10 \mathrm{~g}$ samples at $103^{\circ} \mathrm{C}$ for 24 hours. Unless otherwise stated, moisture contents are reported in wet basis. Equation 1 was used to compute the total mass of moisture removed per unit mass of dry biomass $\left(\mathrm{M}_{\text {loss }}\right)$ from the measured moisture content of samples before $\left(\mathrm{m}_{\mathrm{i}}\right)$ and after grinding $\left(\mathrm{m}_{\mathrm{f}}\right)$. The measured ash, volatile matter and energy content of the loblolly pine woodchips are given in Table 1.

$$
\mathrm{M}_{\text {loss }}=\left(\frac{\mathrm{m}_{\mathrm{i}}}{1-\mathrm{m}_{\mathrm{i}}}\right)-\left(\frac{\mathrm{m}_{\mathrm{f}}}{1-\mathrm{m}_{\mathrm{f}}}\right)
$$

Six drying-grinding sequences were used in this study. A description of these sequences is summarized in Table 2. Woodchips used for each of the drying-grinding sequence was adjusted to initial moisture contents of $12 \%, 30 \%$ or $50 \%$ by adding and mixing predetermined quantity of water. The adjusted moisture samples were then kept in a refrigerator (at temperature of about $4^{\circ} \mathrm{C}$ ) for at least ten days. Before use, samples were removed from the refrigerator to allow for equilibration at room temperature. 
In cases where a second grinding is carried out at lower moisture content (e.g. sequence 50-L-30-S in Table 2), the samples used for the second grinding phase were air-dried to the desired moisture content. At each stage of the drying-grinding sequence, the moisture content of each sample was verified with the ASTM 871-82 moisture content measurement standard. Table 3 shows that the measured moisture contents of samples were slightly different from the targeted moisture content values. This small deviation between actual and targeted moisture contents typically occurs during the artificial adjustment of biomass moisture content (Lam et al., 2008; Oyedeji et al., 2016).

Table 1. Physical and chemical properties of loblolly pine woodchips used in this study ${ }^{\mathrm{a}}$.

\begin{tabular}{lcc}
\hline Property & Standard & Value \\
\hline Ash content $(\%)$ & NREL (Sluiter et al., 2008) & $0.46(0.08)$ \\
Volatile matter content $(\%)$ & ECN 15148 (SIS, 2006) & $85.5(0.19)$ \\
Energy content (MJ/kg) & Calorimeter* & $20.1(0.07)$ \\
\hline${ }^{\text {a }}$ Values of ash, volatile matter, and energy contents are on dry basis. Values in parenthesis are standard deviation from \\
triplicate. \\
$*$ IKA C200 calorimeter (IKA Works, Wilmington, NC)
\end{tabular}

Table 2. Notation and description of selected drying-grinding sequences.

\section{Sequence Notation Description}

$12-\mathrm{S}$

woodchips dried from $50 \%$ to $12 \%$ moisture content, then ground through 3.18 mm screen size

$30-S$

woodchips dried from $50 \%$ to $30 \%$ moisture content, then ground through 3.18 mm screen size

$50-\mathrm{S}$

woodchips ground at $50 \%$ moisture content through $3.18 \mathrm{~mm}$ screen size

30-L-12-S

woodchips dried from $50 \%$ to $30 \%$ moisture content and ground through 6.35 $\mathrm{mm}$ screen size, then dried to $12 \%$ moisture content and ground through 3.18 $\mathrm{mm}$ screen size

50-L-30-S

woodchips ground at $50 \%$ moisture content through $6.35 \mathrm{~mm}$ screen size, then dried to $30 \%$ moisture content and ground through $3.18 \mathrm{~mm}$ screen size 

dried to $12 \%$ moisture content and ground through $3.18 \mathrm{~mm}$ screen size

Table 3. Targeted versus actual moisture content (\%, w.b.) of samples before each grinding operation.

\begin{tabular}{lcccc}
\hline \multirow{2}{*}{$\begin{array}{l}\text { Drying-Grinding } \\
\text { Sequence }\end{array}$} & \multicolumn{2}{c}{ First Grinding Phase } & \multicolumn{2}{c}{ Second Grinding Phase } \\
\cline { 2 - 5 } & Targeted & Actual $^{*}$ & Targeted & Actual \\
\hline 12-S & 12.0 & $11.6(0.1)$ & N/A & N/A \\
$30-\mathrm{L}-12-\mathrm{S}$ & 30.0 & $30.6(0.4)$ & 12.0 & $10.5(0.1)$ \\
$30-\mathrm{S}$ & 30.0 & $30.6(0.4)$ & N/A & N/A \\
$50-\mathrm{L}-12-\mathrm{S}$ & 50.0 & $51.7(0.2)$ & 12.0 & $11.8(0.1)$ \\
$50-\mathrm{L}-30-\mathrm{S}$ & 50.0 & $51.7(0.2)$ & 30.0 & $31.6(0.7)$ \\
$50-\mathrm{S}$ & 50.0 & $51.7(0.2)$ & N/A & N/A \\
\hline
\end{tabular}

N/A means the grinding stage does not exist for the corresponding drying-grinding sequence.

${ }^{a}$ Values in parenthesis are standard deviation from triplicate. In each column

\subsection{Grinding operation and specific grinding energy}

Grinding of loblolly pine woodchips was carried out using a hammer mill (model 10HBLPK, C.S. Bell Co., Tiffin, Ohio) that is fitted with 12 swinging beaters and powered by a $2.24 \mathrm{~kW}$ ( $3 \mathrm{hp}$ ), 3-phase electric motor (model C182T17FB29D, LEESON Electric Corporation, Grafton, Wisc.). The hammer mill was also fitted with either a $3.18 \mathrm{~mm}$ screen or a $6.35 \mathrm{~mm}$ screen depending on the dryinggrinding sequence in Table 2. Hammer mill screen size $3.18 \mathrm{~mm}$ was chosen as the final grinding screen because it has been demonstrated by several studies (Colley et al., 2006; Fasina, 2008; Mani et al., 2006a; Tabil and Sokhansanj, 1996) as suitable for the production of pellets. Biomass densification by pelletizing is a common method used to optimize biomass transportation logistics.

For each run, $3 \mathrm{~kg}$ of wet samples was processed through the hammer mill at a rate of $19.0 \mathrm{~kg} / \mathrm{hr}$. The active electric energy used during grinding was measured by a watt-hour meter ( $\pm 1 \%$ accuracy) (model A3314/02, EZ meter, Santa Ynez, Cal.). Prior to grinding, power consumption when running the hammer mill empty (no-load power) was determined to be $0.81 \pm 0.02 \mathrm{~kW}$. Specific grinding energy consumption was computed using Equation 2. Each experimental treatment was conducted in triplicates.

$$
E=\frac{E_{t}-E_{p}}{M_{d r y}}
$$


where $\mathrm{E}$ is the specific grinding energy consumed $\left(\mathrm{kJ} / \mathrm{kg} \mathrm{d.b.),} \mathrm{E}_{\mathrm{t}}\right.$ is the total grinding energy consumed $(\mathrm{kJ}), \mathrm{E}_{\mathrm{p}}$ is the parasitic energy consumed $(\mathrm{kJ})$, and $\mathrm{M}_{\mathrm{dry}}$ is the dry matter mass of biomass $(\mathrm{kg})$. Since the moisture contents of the samples after the drying-grinding sequence vary from about $12 \%$ to about $50 \%$, all the samples were oven dried at $55^{\circ} \mathrm{C}$ until constant weight was reached to nullify the effect of moisture content on the physical and flow characteristics (see methodologies below) of the grinds.

\subsection{Particle size and particle size distribution}

Particle size and particle size distribution of the grinds were determined with a Ro-Tap test sieve shaker (model RX - 29, W.S. Tyler, Mentor, Ohio) according to ASABE standard S319.4 (ASABE, 2008). The sieve shaker was fitted with the following 10 ISO screens: $2.380 \mathrm{~mm}, 1.680 \mathrm{~mm}, 1.000 \mathrm{~mm}, 0.707$ $\mathrm{mm}, 0.420 \mathrm{~mm}, 0.250 \mathrm{~mm}, 0.125 \mathrm{~mm}, 0.088 \mathrm{~mm}, 0.053 \mathrm{~mm}, 0.044 \mathrm{~mm}$ (ISO numbers: 8, 12, 18, 25, 40, 60, 120, 170, 270, and 325 respectively). About $100 \mathrm{~g}$ of grinds was placed on the top sieve of the nest of sieves and a sieving time of 15 minutes was applied. At the end of the sieving period, the mass of material retained on the sieves were used in developing the particle size distribution, and in estimating the geometric mean diameter and the geometric standard deviation of the grinds.

\subsection{Aspect Ratio}

The aspect ratio of the particles of each grind sample was measured with an image analyzer (model Camsizer, Retsch Technology, Haan, Germany) that is fitted with two cameras that in combination measure particles in the size range of $30 \mu \mathrm{m}-30 \mathrm{~mm}$. For each sample, about $500 \mathrm{~g}$ of sample was loaded onto the hopper of the analyzer and then conveyed by a vibratory feeder into the measurement field of the two cameras. The software provided by the equipment manufacturer captured the image frames of the particles and computed the aspect ratio distribution of samples.

\subsection{Bulk density and tap density}

The bulk density of grinds was measured with a bulk density apparatus (Burrows Co., Evanston, Ill) that consisted mainly of an $1137 \mathrm{~mm}^{3}$ container and a hopper. The container was filled with grinds through the hopper, which was $0.6 \mathrm{~m}$ above the top edge of the container. Grinds in the container were leveled with the top edge of the container. The bulk density of grinds was calculated as the ratio of mass of the sample that filled the container to the volume of the container. 
A tap density tester (model TD-12, Pharma-Alliance Group Inc., Valencia, Cal.) was used for tap density measurement. A $250 \mathrm{~mm}^{3}$ cylinder was filled with grinds, weighed, tapped 500 times, and then tapped 750 times. If the difference between the volume of grinds after the initial 500 taps and the volume of grinds after the 750 taps was less than $2 \%$, the tapping process was completed, else the process was repeated. Tap density was computed as the ratio of mass of grinds to the volume of grinds after tapping.

\subsection{Flow index and compressibility index}

The flow index of grinds was measured using a powder flow tester (model PFT, Brookfield Engineering Laboratories, Inc., Middleboro, Mass.). The equipment has a $152.40 \mathrm{~mm}$ diameter annular split cell sample trough and a vane lid (with 18 small compartments). The sample trough was filled with samples of known mass and leveled using the shaping blade. The flow tester was then operated to shear the grinds packed between the vane lid and trough. Flow index was obtained from the software of the tester.

The compressibility of grinds was measured with a texture analyzer (model TA-HD, Stable Microsystems, Surrey, U.K.). A cylinder (49.55 mm internal diameter by $101.83 \mathrm{~mm}$ height) was filled with grinds and weighed. The software of the texture analyzer was programmed to compress the sample in the cylinder (with a $49.00 \mathrm{~mm}$ diameter piston attached to the cross arm of the texture analyzer) at the rate of $1 \mathrm{~mm} / \mathrm{s}$ until a consolidating pressure of $6 \mathrm{kPa}$ was reached. The compressibility index (CI) for each sample was calculated as follows:

$$
C I=100 \frac{V_{i}-V_{f}}{V_{i}}
$$

where $V_{i}$ and $V_{f}$ are volume of grinds $\left(\mathrm{m}^{3}\right)$ before and after consolidation, respectively.

\subsection{Drying energy consumption}

The energy required to dry biomass before and/or after grinding is important in the assessment of energy consumption during biomass preprocessing. The average energy $\left(\mathrm{E}_{\mathrm{drying}}\right)$ that will be needed to dry the chips to $8 \%$ moisture content (after accounting for moisture loss during the grinding phase of each drying-grinding sequence) was calculated based on the assumption that a hot-air rotary dryer with typical specific energy consumption, $S_{\mathrm{m}}$, of $4140 \mathrm{~kJ} / \mathrm{kg}$ (Mujumdar, 2003) will be used to dry the wood chips (equation 4). 


$$
\mathrm{E}_{\mathrm{drying}}=S_{m} \Sigma \Delta M
$$

where $\Delta \mathrm{M}$ is the total moisture ( $\mathrm{kg}$ water per kg solid mass) removed due to drying.

\subsection{Data analysis}

Experimentation followed a completely randomized design (CRD) with three replications. All statistical analyses were performed using SAS software (SAS 9.3, SAS Institute Inc., Cary, N.C.). Analysis of variance (ANOVA) was implemented to investigate the significance of the differences among treatments at a significance level of 5\%. All pairwise difference testing between treatments were carried out using Tukey's HSD test.

\section{Results and discussion}

\subsection{Particle size and particle size distribution}

The particle size and particle size distribution of biomass grinds are important because they influence the performance of downstream processes. In addition, the ratio of the particle size of woodchips before grinding to the particle size of resulting grinds after grinding is proportional to the specific grinding energy. Figure 1 shows the particle size distribution of grinds produced in this study. Grinds produced from all the drying-grinding sequences followed a similar particle size distribution. However, it seems that as the grinding moisture content reduced, the lower the likelihood that the particle size distribution is skewed towards the larger particles. The highest mass fraction was retained on ISO sieve number 18 (1.00 mm aperture opening). This is not surprising since the last grinding in the grinding sequence was carried out with a hammer screen size of $3.18 \mathrm{~mm}$. The observed particle size distributions were comparable to those reported by Probst et al. (2013) for corn and Miao et al. (2011) for miscanthus, switchgrass and willow.

Table 4 shows that the particle size of grinds (geometric mean diameter) was significantly affected ( $\mathrm{p}<$ $0.05)$ by drying-grinding sequence. Sample $50-\mathrm{S}(0.649 \mathrm{~mm})$ had the smallest geometric mean diameter, while $30-\mathrm{S}(0.835 \mathrm{~mm})$ had the largest geometric mean diameter. It was observed during the grinding process that 50-S samples were more ductile and more difficult to grind. This sample therefore had more contact with the hammers of the grinder and therefore produced higher number of fines (Figure 1). The geometric mean diameter of grinds with the same moisture content before the final grinding phase (30-S and 50-L-30-S, 12-S, 30-L-12-S, and 50-L-12-S) was not significantly different

$(\mathrm{p}<0.05)$. Furthermore, the addition of a second grinding and drying phase significantly affected the 
geometric mean diameter of grinds produced. With initial moisture content of 30\%, the geometric mean diameter produced was significantly reduced $(\mathrm{p}<0.05)$ from $0.835 \mathrm{~mm}(30-\mathrm{S})$ to $0.738 \mathrm{~mm}(30-\mathrm{L}-$ 12-S), by the addition of a second drying and grinding phase. However, with an initial moisture content of 50\%, the addition a second drying and/or grinding phases resulted in a significant increase (p $<0.05)$ in the geometric mean diameter of grinds.

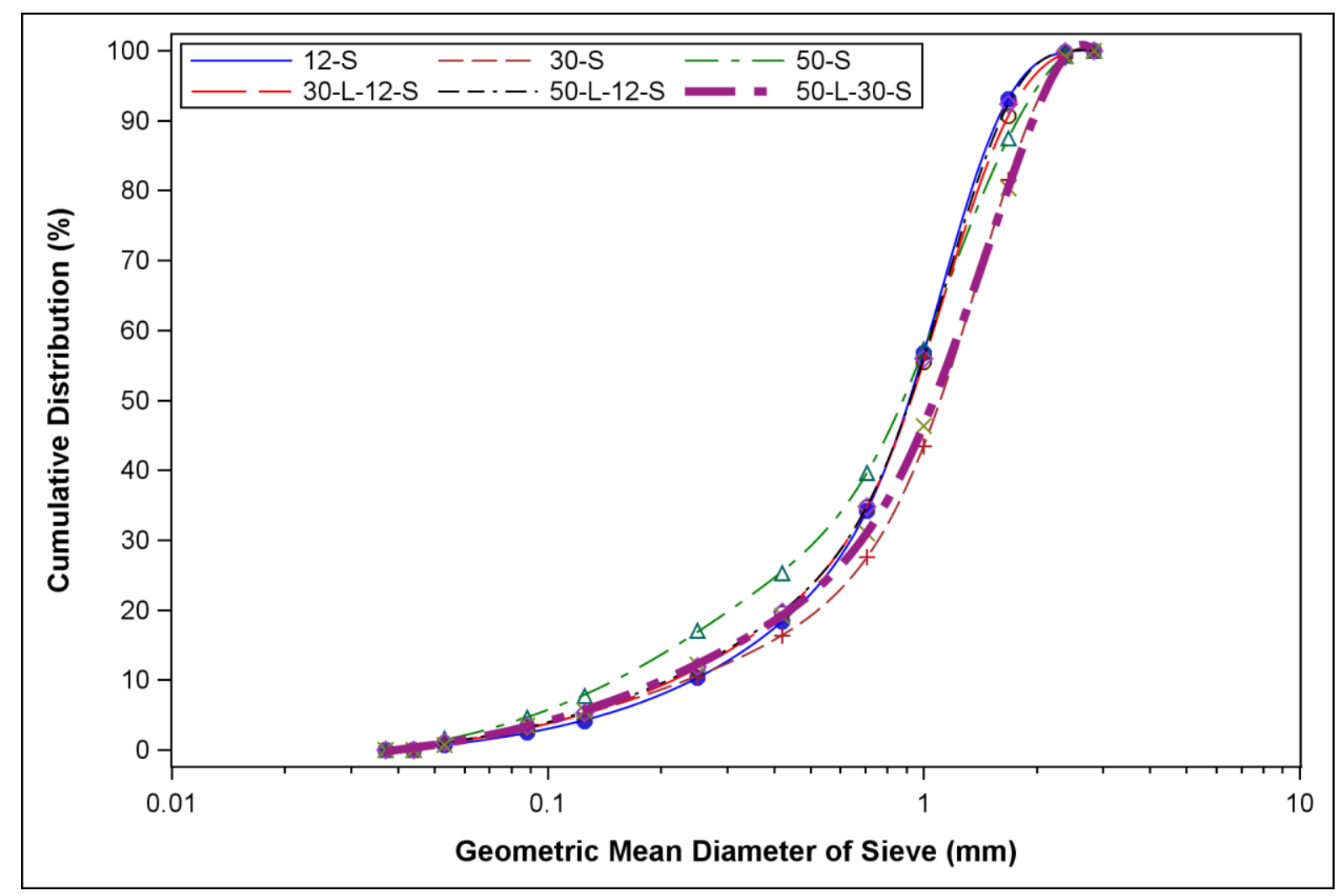

Figure 1. Effect of drying-grinding sequence on the particle size distribution of grinds.

Table 4. Effect of drying-grinding sequence on geometric mean diameter and geometric standard deviation of grinds ${ }^{\mathrm{a}}$.

\begin{tabular}{lcc}
\hline $\begin{array}{l}\text { Drying-Grinding } \\
\text { Sequence }\end{array}$ & $\begin{array}{c}\text { Geometric Mean } \\
\text { Diameter }(\mathbf{m m})\end{array}$ & $\begin{array}{c}\text { Geometric Standard } \\
\text { Deviation }(\mathbf{m m})\end{array}$ \\
\hline $12-\mathrm{S}$ & $0.776(0.032)^{\mathrm{b}, \mathrm{c}}$ & $0.640(0.004)^{\mathrm{d}}$ \\
$30-\mathrm{L}-12-\mathrm{S}$ & $0.738(0.003)^{\mathrm{c}}$ & $0.671(0.008)^{\mathrm{c}}$ \\
$30-\mathrm{S}$ & $0.835(0.014)^{\mathrm{a}}$ & $0.820(0.002)^{\mathrm{a}}$ \\
$50-\mathrm{L}-12-\mathrm{S}$ & $0.740(0.013)^{\mathrm{c}}$ & $0.654(0.015)^{\mathrm{c}, \mathrm{d}}$
\end{tabular}




$\begin{array}{lcc}50-\mathrm{L}-30-\mathrm{S} & 0.802(0.003)^{\mathrm{a}, \mathrm{b}} & 0.841(0.005)^{\mathrm{a}} \\ 50-\mathrm{S} & 0.649(0.016)^{\mathrm{d}} & 0.715(0.007)^{\mathrm{b}}\end{array}$

a Values in parenthesis are standard deviation from triplicate. In each column, values with the same letter are not significantly different $(\mathrm{p}<0.05)$.

In general, the grinds had high geometric standard deviations which is typical of ground biomass feedstocks (Ghorbani et al., 2010; Himmel et al., 1986). The geometric standard deviation of grinds varied from $0.640 \mathrm{~mm}$ (sequence $12-\mathrm{S}$ ) to $0.835 \mathrm{~mm}$ (sequence $30-\mathrm{S}$ ). However, the geometric standard deviation of samples with higher amount of finer fractions (50-S and 50-L-30-s) were higher than the corresponding geometric mean - an indication of the relative influence of the fines on the geometric mean. Similar results were previously reported by Fasina (2008), Mani et al. (2006b) and Naimi et al. (2016) for peanut hulls, corn stover and pine.

\subsection{Aspect ratio}

Figure 2 shows the aspect ratio distribution of the grinds. Aspect ratio was calculated by the camsizer software as the ratio of length to width of particles. The greater the aspect ratio of a particle is above 1, the more elongated the particle. Over $60 \%$ of the particles in each grind sample had aspect ratios greater than 2.5 - thus confirming the elongated nature of the particles. In addition, the aspect ratio distributions of the grinds were skewed and were similar to the skewed particle size distribution behavior for all the drying-grinding sequence utilized in this study. Grinds processed with sequence 12$\mathrm{S}$ were the most elongated while grinds processed with sequences 50-S and 50-L-30-S produced relatively the least elongated. We attribute this result to the differences in influence of moisture content and particle size prior to grinding on breakage behavior of biomass grinds. When moisture content is increased, particles breakage occurs more along axis parallel to the fiber than across the fiber. More string-shaped particles with high aspect ratio are therefore produced. The result was also supported by the images of sample morphology in Figure 3. Miao et al. (2011) also reported high aspect ratios for miscanthus and switchgrass particles that varied from 5.0 to 16.7. Although high aspect ratio of particles can cause flowability challenges, Momenikouchaksaraei (2013) and Liu et al. (2004) reported that these elongated particles have increased rate of heat transfer because of the increase in surface area. 


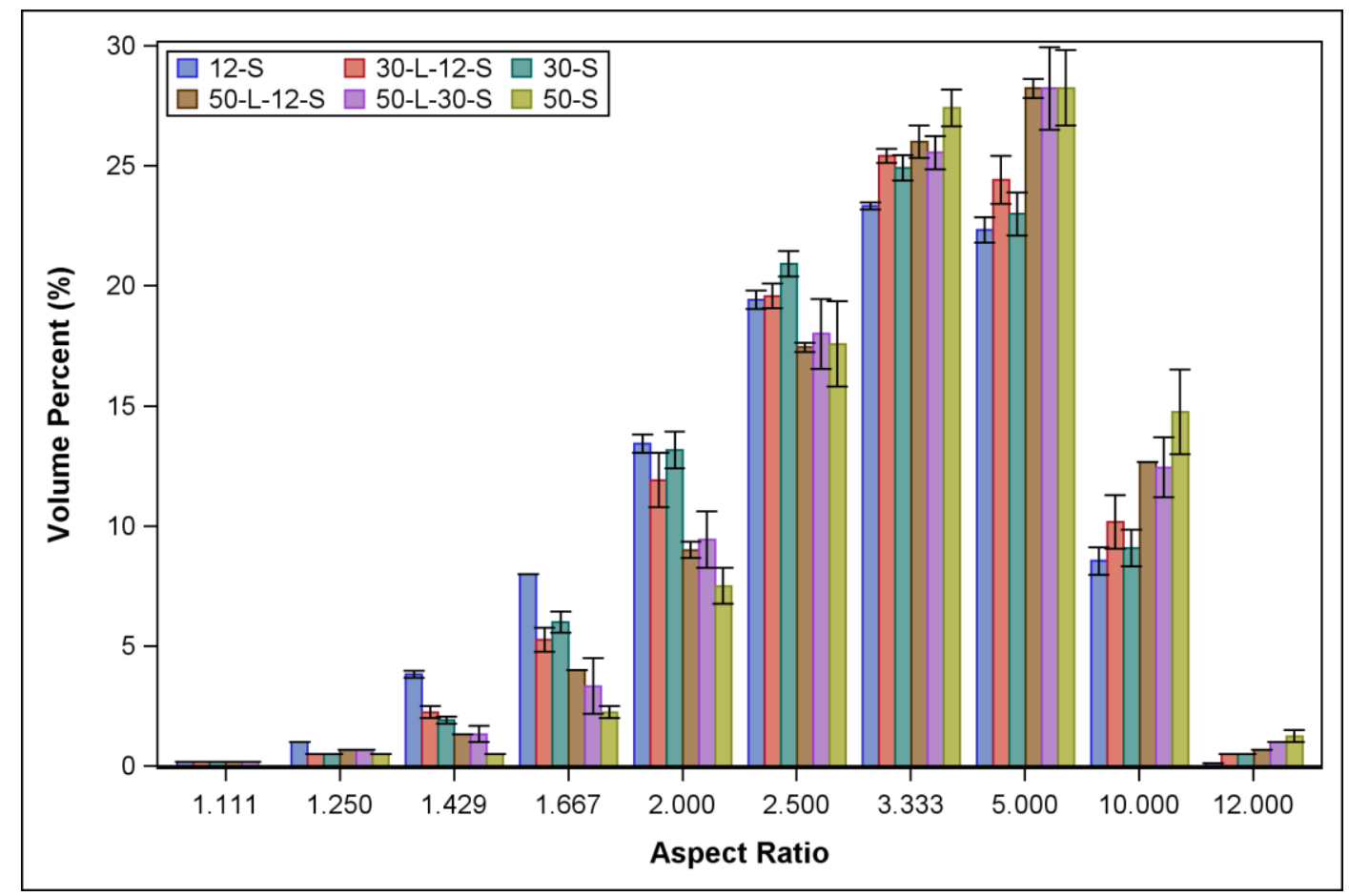

Figure 2. Effect of drying-grinding sequence on the aspect ratio distribution of grinds. Error bars are standard deviations based on triplicate measurements.

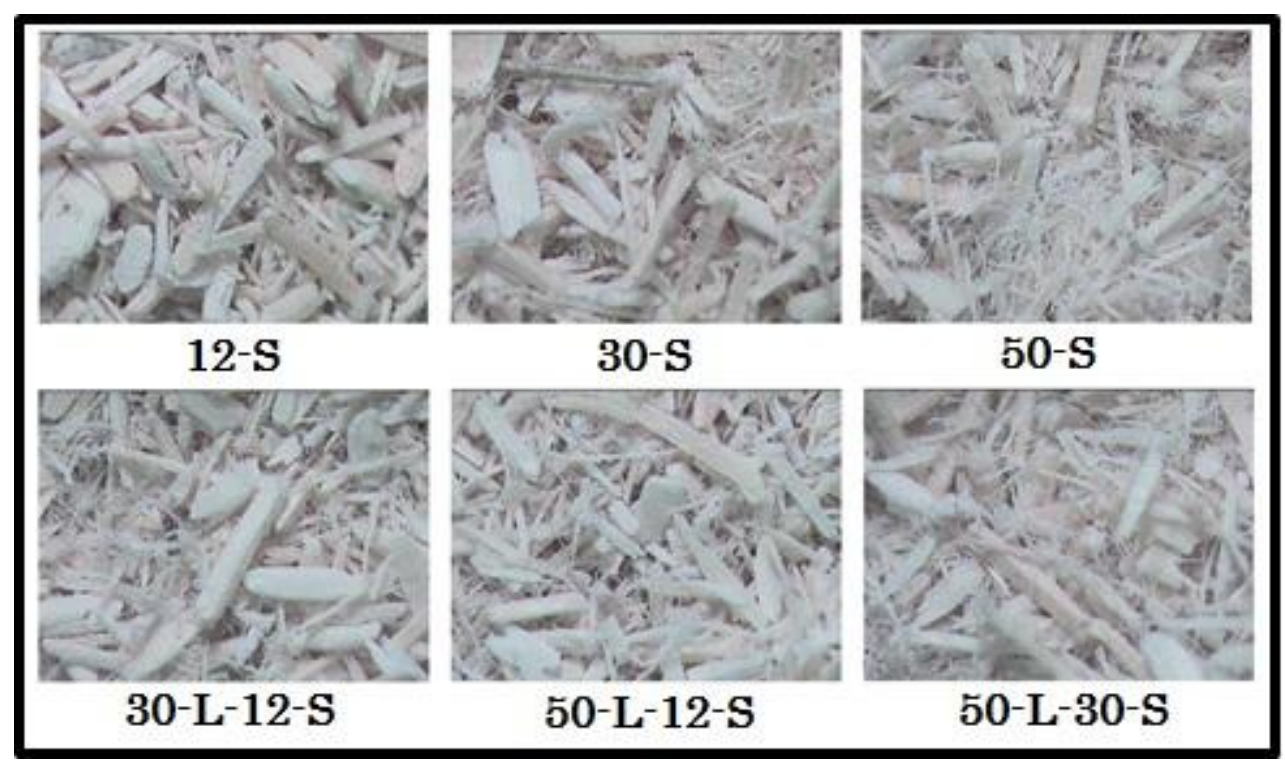

Figure 3. Morphology of grinds from drying-grinding sequence. 


\subsection{Bulk density and tap density}

Analysis of variance showed that the bulk density of grinds was significantly affected $(\mathrm{p}<0.05)$ by drying-grinding sequence and varied from $98.0 \mathrm{~kg} / \mathrm{m}^{3}$ to $267.1 \mathrm{~kg} / \mathrm{m}^{3}$ (Table 5). The bulk density of $50-\mathrm{L}-12-\mathrm{S}$ and $30-\mathrm{S}$ were however not significantly different $(\mathrm{p}<0.05)$. When the bulk density data was examined in relation to the observed morphology of grinds in Figure 3, it was observed that fluffiness of grinds contributed to the decrease in bulk density. This observation can be explained by the fact that fluffiness of grinds leads to the formation of void spaces, which increase porosity. To assess the effect of second drying and grinding phase, 50-S and 50-L-30-S, 50-S and 50-L-12-S, and 30-S and 30-L-12-S were paired and compared. These comparisons showed that except for 12-S, one phase grinding produced lower bulk density, meaning that second drying and grinding phase increased bulk density by reducing fluffiness of grinds.

After tapping, the density of grinds (tap density) increased for all the drying-grinding sequence in this work. The implication of this result is that grinds will compact during transportation, and this has the potential to cause handling difficulties when the grinds are discharged from shipping and storage containers. The measured tap density of grinds was ranged from $342.6 \mathrm{~kg} / \mathrm{m}^{3}$ (12-S) to $153.7 \mathrm{~kg} / \mathrm{m}^{3}$ (50-S). It was also observed that tap density of grind was influenced by the drying-grinding sequence. Hausner ratio (the ratio of the tap bulk density to the bulk density of grinds) were used to assess the fluidization behavior and the cohesiveness of the grinds. Values of Hausner ratio less than 1.25 are easily fluidized while powders with Hausner ratio greater than 1.4 are difficult to fluidize (BarbosaCanovas et al., 2005). Based on the calculated Hausner ratio (varied from 1.28 to 1.57 - Table 5) that was significant affected $(\mathrm{P}<0.05)$ by the drying-grinding sequence, the grinds will not easily fluidize but it seems that partial drying/partial grinding sequence appear to reduce the flowability of the grinds.

\subsection{Flow index and compressibility index}

Flow index of powder material is often used to classify the degree of flowability of the material, as shown in Table 6. The flow index values (Figure 4) indicate that grinds produced by all dryinggrinding sequences studied are cohesive with the maximum and minimum flow indices of 3.01 (sequence 12-S) and 2.09 (sequence 50-S), respectively, thus confirming the flowability trend obtained from Hausner ratio as reported in the previous section. Statistical testing established that flow index was significantly affected $(\mathrm{p}<0.05)$ by the drying-grinding sequence. Our hypothesis is that the 
variations in the morphology of the grinds (Figure 3) caused the differences in inter-particle interactions and entanglements - thereby affecting the flowability of the grinds.

Table 5. Effect of drying-grinding sequence on bulk and tap densities of grinds

\begin{tabular}{lccc}
\hline $\begin{array}{l}\text { Drying-Grinding } \\
\text { Sequence }\end{array}$ & $\begin{array}{c}\text { Bulk Density } \\
\left(\mathbf{k g} / \mathbf{m}^{\mathbf{3}}\right)\end{array}$ & $\begin{array}{c}\text { Tap Density } \\
\left(\mathbf{k g} / \mathbf{m}^{\mathbf{3}}\right)\end{array}$ & Hausner Ratio \\
\hline $12-\mathrm{S}$ & $267.1^{\mathrm{a}}(3.24)$ & $342.6^{\mathrm{a}}(0.62)$ & $1.28^{\mathrm{c}}(0.02)$ \\
$30-\mathrm{L}-12-\mathrm{S}$ & $194.8^{\mathrm{b}}(6.55)$ & $252.8^{\mathrm{b}}(3.94)$ & $1.28^{\mathrm{c}}(0.03)$ \\
$30-\mathrm{S}$ & $165.5^{\mathrm{c}}(1.95)$ & $212.3^{\mathrm{d}}(4.84)$ & $1.57^{\mathrm{a}}(0.06)$ \\
$50-\mathrm{L}-12-\mathrm{S}$ & $173.4^{\mathrm{c}}(0.39)$ & $231.7^{\mathrm{c}}(1.86)$ & $1.30^{\mathrm{b}, \mathrm{c}}(0.05)$ \\
$50-\mathrm{L}-30-\mathrm{S}$ & $130.8^{\mathrm{d}}(0.98)$ & $181.9^{\mathrm{e}}(2.49)$ & $1.34^{\mathrm{b}, \mathrm{c}}(0.01)$ \\
$50-\mathrm{S}$ & $98.0^{\mathrm{e}}(0.91)$ & $153.7^{\mathrm{f}}(4.11)$ & $1.39^{\mathrm{b}}(0.01)$
\end{tabular}

${ }^{\text {a }}$ Values in parenthesis are standard deviation from triplicate. In each column, values with the same letter are not significantly different $(\mathrm{p}<0.05)$.

Table 6. Classification of powder flowability by flow index (Jenike, 1964)

\section{Flowability}

\begin{tabular}{lcccc}
\cline { 2 - 4 } & Very Cohesive & Cohesive & Easy Flowing & Free Flowing \\
\hline Flow Index $(\mathrm{FI})$ & FI $<2$ & $2<$ FI $<4$ & $4<$ FI $<10$ & FI $>10$
\end{tabular}




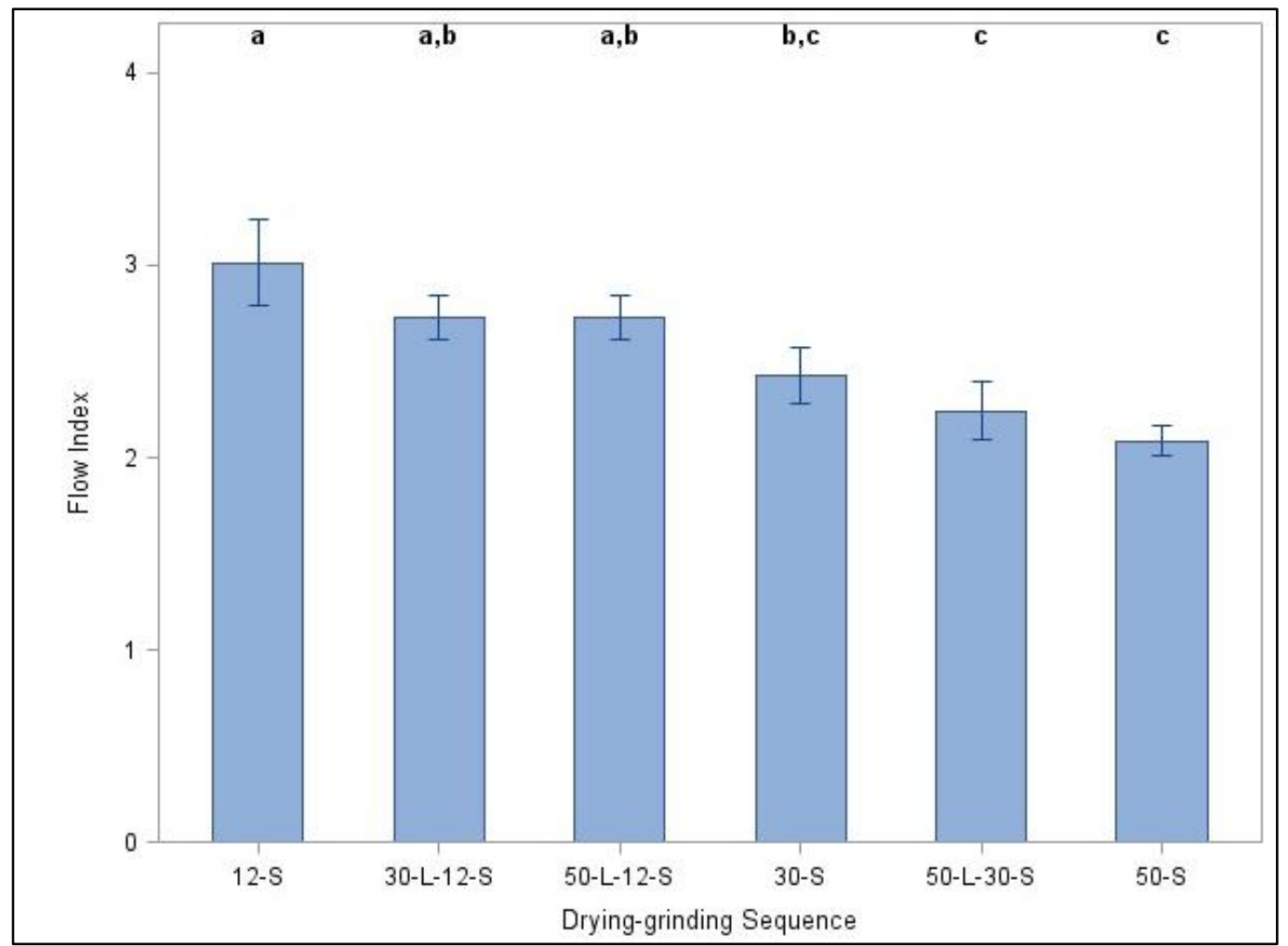

Figure 4. Effect of drying-grinding sequence on flow index of grinds (bars with the same letter are not significantly different $(\mathrm{p}<0.05)$.

The compressibility index for a powder material is the extent to which the volume of the material reduced when subjected to a consolidating force. Compressibility index has been used by some researchers (Bernhart and Fasina, 2009; Gonclaves et al., 2015) to evaluate flowability because compressibility index is also a measure of the magnitude of the inter-particle force of adhesion. The higher the compressibility index value, the lower the flowability of materials (Fayed and Skocir, 1996). Additionally, Crawford et al. (2015) pelletized corn stover, hybrid poplar, switchgrass, and Miscanthus and reported that compressibility of material is inversely proportional to the amount of energy required for pelletization.

The compressibility index of grinds subjected to $6 \mathrm{kPa}$ consolidating pressure was significantly affected $(\mathrm{p}<0.05)$ by drying-grinding sequence (Figure 5). Among the drying-grinding sequences studied, 50-S grinds was the most compressible with compressibility of $44.6 \%$, while grinds from sequence 12-S was the least compressible (compressbility of 10.5\%). The compressibility index of 30L-12-S grinds was not significantly different $(\mathrm{p}<0.05)$ from the compressibility index of $12-\mathrm{S}$. Similarly, the compressibility index of 50-L-30-S, 30-S, and 50-L-12-S were not significantly different $(\mathrm{p}<0.05)$. The compressibility data again confirmed the resutls obtained from Hausner ratio (using tap 
density data) and the flow tester that showed that the flowability of the grinds significantly became poorer when grinding is carried out at moisture content of $30 \%$ or $50 \%$.

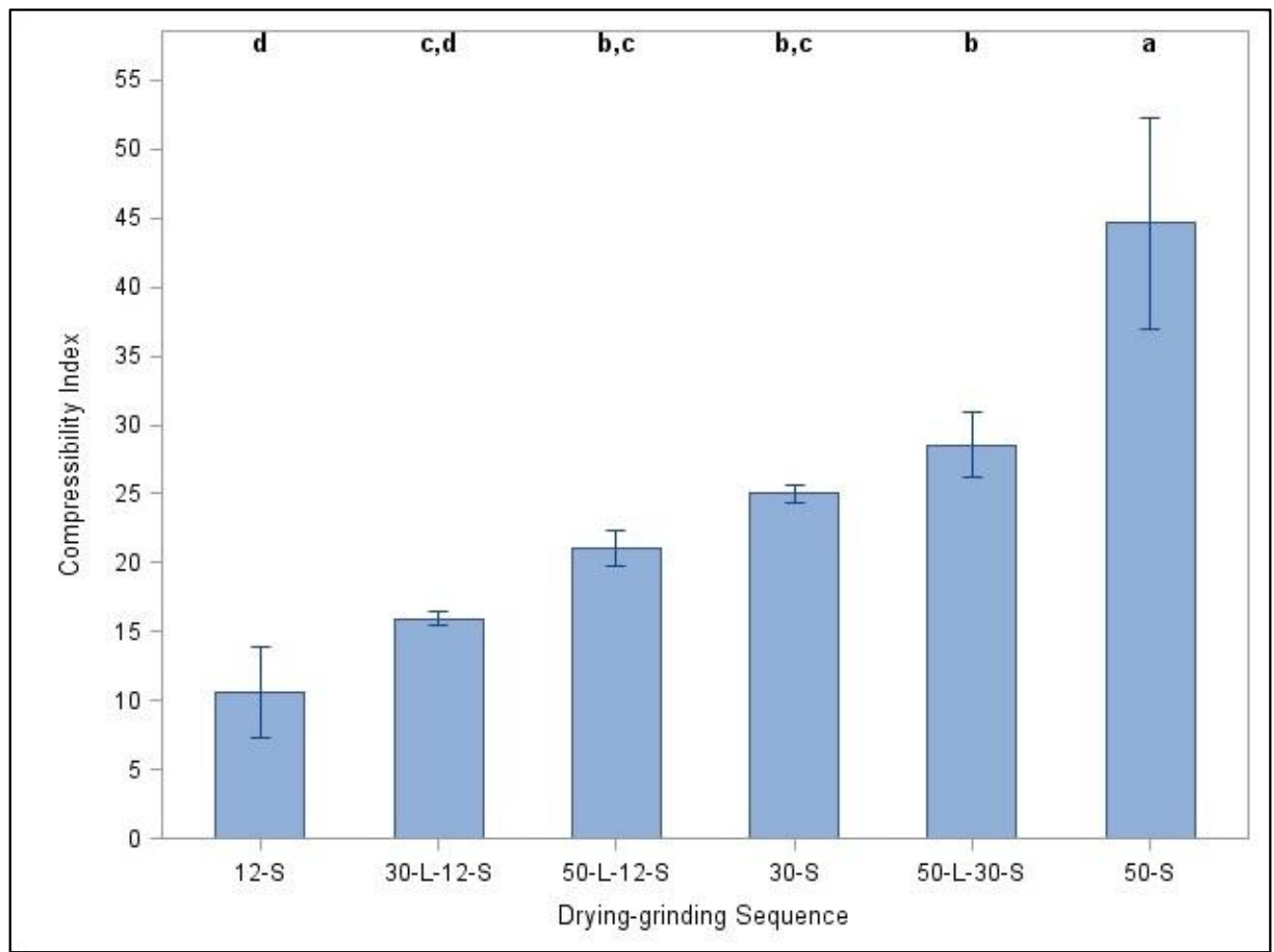

Figure 5. Effect of drying-grinding sequence on compressibility index (bars with the same letter are not significantly different $(\mathrm{p}<0.05))$.

\subsection{Specific grinding energy consumption}

In general, the specific grinding energy consumption of loblolly pine woodchips were significantly affected by the drying-grinding sequence (Table 7). However, there was no significant difference between the specific grinding energy consumption for sequences 30-L-12-S and 50-L-12-S. As expected, the highest specific energy was consumed by $50-\mathrm{S}$ sequence and the least specific energy was consumed by $12-\mathrm{S}$ sequence, because biological materials typically become tougher as moisture content increases - requiring more grinding to permanently deform and grind them. This result agrees with the results from study carried out by Mani et al. (2004) that measured the energy required to grind for wheat straw through a $3.2 \mathrm{~mm}$ hammer mill screen increasing from $44.6 \mathrm{~kJ} / \mathrm{kg}$ d.b. to $100.9 \mathrm{~kJ} / \mathrm{kg}$ d.b. when moisture content increased from $8.3 \%$ to $12.0 \%$. The specific grinding energy values in Table 7 are also similar to the values reported Miao et al. (2011) during the grinding of miscanthus. Furthermore, the specific grinding energy for each grinding stage is listed in Table 7. For the first 
grinding phase, the specific grinding energy values obtained are in consonant with data from our previous study (Oyedeji et al., 2016).

Table 7. Effect of drying-grinding sequence on specific grinding energy consumption and total energy consumption $^{\mathrm{a}}$.

\begin{tabular}{|c|c|c|c|c|}
\hline \multirow{2}{*}{$\begin{array}{l}\text { Drying-Grinding } \\
\text { Sequence }\end{array}$} & \multicolumn{3}{|c|}{ Specific Grinding Energy Consumption (kJ/kg d.b.) } & \multirow{2}{*}{$\begin{array}{c}\text { Specific Drying } \\
\text { Energy Consumption } \\
(\mathbf{k J} / \mathbf{k g} \text { d.b. })\end{array}$} \\
\hline & $\begin{array}{c}\text { First Grinding } \\
\text { Phase }\end{array}$ & $\begin{array}{c}\text { Second } \\
\text { Grinding Phase }\end{array}$ & Total & \\
\hline $12-\mathrm{S}$ & $211.6(5.7)$ & N/A & $211.6^{\mathrm{e}}(5.7)$ & $3933.0^{\mathrm{a}}(2.7)$ \\
\hline $30-\mathrm{L}-12-\mathrm{S}$ & $189.2(3.7)$ & $99.5(7.0)$ & $288.6^{\mathrm{d}}(6.6)$ & $3673.3^{\mathrm{b}}(62.2)$ \\
\hline $30-\mathrm{S}$ & $572.8(3.2)$ & N/A & $572.8^{\mathrm{b}}(3.2)$ & $3020.5^{\mathrm{c}}(0.3)$ \\
\hline $50-\mathrm{L}-12-\mathrm{S}$ & $164.7(13.6)$ & $110.4(4.0)$ & $275.1^{\mathrm{d}}(13.5)$ & $3231.1^{\mathrm{c}}(121.2)$ \\
\hline $50-\mathrm{L}-30-\mathrm{S}$ & $164.7(13.6)$ & $274.2(7.5)$ & $438.8^{\mathrm{c}}(11.9)$ & $2665.3^{\mathrm{d}}(128.2)$ \\
\hline $50-\mathrm{S}$ & $818.2(27.1)$ & N/A & $818.2^{\mathrm{a}}(27.1)$ & $1580.7^{\mathrm{e}}(40.4)$ \\
\hline
\end{tabular}

\footnotetext{
${ }^{a}$ Values in parenthesis are standard deviation from at least three replicates. Specific drying energy consumption values were calculated based on the actual moisture content of samples as listed in Table 3. In each column, values with the same letter are not significantly different $(\mathrm{p}<0.05)$. N/A means the grinding stage does not exist for the corresponding drying-grinding sequence.
}

Sequences 50-L-30-S and 50-L-12-S required $543 \mathrm{~kJ} / \mathrm{kg}$ d.b. and $379 \mathrm{~kJ} / \mathrm{kg}$ d.b. less specific grinding energy than sequence 50-S, respectively. Similarly, sequence 30-L-12-S required $283 \mathrm{~kJ} / \mathrm{kg}$ d.b. less specific grinding energy than sequence $30-\mathrm{S}$. These results show that the addition of the second drying and grinding sequence reduces the energy consumption during grinding of high moisture biomass. To eliminate the possibility that the reduction in specific grinding energy consumption is entirely due to moisture reduction, we compared the value of specific grinding energy consumption for sequences 50L-30-S (439 kJ/kg d.b.) and 30-S (573 kJ/kg d.b.). As aforementioned, the higher the moisture content before grinding, the higher the energy consumption. However, the specific grinding energy consumption for sequence 50-L-30-S was lower than the specific grinding energy consumption for sequence $30-\mathrm{S}$. The reduction in grinding energy may therefore be attributed to the combined effect of second phase drying and grinding. 


\subsection{Specific drying energy consumption}

Moisture is usually lost during grinding because of conversion of some of the applied grinding mechanical energy to heat energy (Havimo and Hari, 2010) that then cause vaporization of some of the moisture content of the biomass. The direct implication of moisture loss during grinding is that the amount of water needed to be taken off in the course of subsequent drying process is reduced. This moisture reduction translates into a decrease in the required drying energy requirement.

The moisture content of samples after each grinding stage was measured (Table 8). The moisture content data shows that the moisture loss during grinding increased as the initial moisture contents of sample increased. Using the procedure outlined in the methodology section after factoring the moisture removed during grinding, the estimated specific drying energy for the grinds ranged from $1581 \mathrm{~kJ} / \mathrm{kg}$ d.b. (sequence $50-\mathrm{S}$ ) to $3933 \mathrm{~kJ} / \mathrm{kg}$ d.b. (sequence 12-S). A careful study of the trend for the estimated drying energy and the specific grinding energy requirements shows a trade-off between both (Table 7). This trade-off was because grinding of higher moisture content feedstock result in higher specific grinding energy requirement and higher moisture loss, which subsequently reduces the specific drying energy requirement.

Table 8. Effect of drying-grinding sequence on moisture loss during grinding ${ }^{\mathrm{a}}$.

\begin{tabular}{lccc}
\hline $\begin{array}{l}\text { Drying-grinding } \\
\text { Sequence }\end{array}$ & $\begin{array}{c}\text { Moisture Content } \\
\text { after First } \\
\text { Grinding Phase }\end{array}$ & $\begin{array}{c}\text { Moisture Content } \\
\text { after Second } \\
\text { Grinding Phase }\end{array}$ & $\begin{array}{c}\text { Moisture Loss during } \\
\text { Grinding (kg water/ kg dry } \\
\text { biomass) }\end{array}$ \\
\hline $12-\mathrm{S}$ & $9.02(0.05)$ & N/A & $0.03^{\mathrm{f}}(0.00)$ \\
$30-\mathrm{L}-12-\mathrm{S}$ & $26.0(0.82)$ & $9.98(0.23)$ & $0.10^{\mathrm{e}}(0.01)$ \\
$30-\mathrm{S}$ & $15.8(0.01)$ & $\mathrm{N} / \mathrm{A}$ & $0.25^{\mathrm{c}}(0.00)$ \\
$50-\mathrm{L}-12-\mathrm{S}$ & $47.3(0.85)$ & $9.4(0.10)$ & $0.20^{\mathrm{d}}(0.03)$ \\
$50-\mathrm{L}-30-\mathrm{S}$ & $47.3(0.85)$ & $22.8(0.03)$ & $0.34^{\mathrm{b}}(0.03)$ \\
$50-\mathrm{S}$ & $31.9(0.45)$ & N/A & $0.60^{\mathrm{a}}(0.01)$
\end{tabular}

\footnotetext{
${ }^{a}$ All values were calculated based on the achieved moisture content as listed in Table 3. Values in parenthesis are standard deviation from at least three replicates. In each column, values with the same letter are not significantly different $(p<0.05)$. N/A means the grinding stage does not exist for the corresponding drying-grinding sequence.
} 
Table 7 shows that the drying-grinding sequence significantly $(\mathrm{p}<0.05)$ influenced the energy required to dry and grind loblolly pine woodchips. Miao et al. (2011) also reported that the position of grinding operation in biomass logistics chain influences the efficiency of the biomass logistics chain. The drying energy consumption data also showed that higher energy savings can be achieved by grinding samples with higher moisture content. For example, the drying energy consumption for sequence 50-S was 1581 $\mathrm{kJ} / \mathrm{kg}$ d.b., and about 2.5 times lower than that of sequence 12-S. This result is due to the fact that the drying energy saved by grinding at high moisture content exceeds the increase in grinding energy consumption.

\section{Conclusions}

Six drying-grinding sequences were evaluated according to grinding energy consumption, drying energy consumption, and particle properties. Although the particulate size distributions of resulting grinds were similar, the geometric mean diameter and geometric standard deviations were significantly different ( $\mathrm{p}<0.05$ ). The bulk density and tap density of grinds varied from $267.1 \mathrm{~kg} / \mathrm{m}^{3}$ to $98.0 \mathrm{~kg} / \mathrm{m}^{3}$ and from $342.6 \mathrm{~kg} / \mathrm{m}^{3}$ to $153.7 \mathrm{~kg} / \mathrm{m}^{3}$, respectively. This information would be useful in the design of transportation and storage systems for each of the evaluated drying-grinding sequence. The flowability of resulting grinding was also measured to provide valuable data needed for flow modeling and simulation. Grinding of loblolly pine woodchips carried out at approximate high moisture contents of $30 \%$ and $50 \%$ produced fluffy grinds, which had lower flow index and higher compressibility index. The specific grinding energy requirement was highest for the sequence 50-S and lowest for the sequence 12-S. However, because moisture loss during grinding increased as the moisture content of samples before grinding increased, the amount of energy required for drying after grinding drastically reduced. The least drying energy requirement was estimated to be $1581 \mathrm{~kJ} / \mathrm{kg}$ d.b. at sequence $50-\mathrm{S}$ and the highest total drying energy requirement was $3933 \mathrm{~kJ} / \mathrm{kg}$ d.b. at sequence $12-\mathrm{S}$.

In summary, the results from this study show that energy consumption during biomass processing and the properties of resulting particles are affected by the sequence used to dry and grind biomass. The information provided in this paper will guide biorefineries in choosing the drying and grinding sequence that is appropriate for their process, and how the drying-grinding sequences will affect these downstream processes. 


\section{Acknowledgements}

We gratefully acknowledge funding support from USDA National Institute of Food and Agriculture (under S1041 multistate project) and from the Southeast Partnership for Integrated Biomass Supply

Systems (IBSS). The IBSS partnership is supported by Agriculture and Food Research Initiative Competitive Grant no. 2011-68005-30410 from the USDA National Institute of Food and Agriculture.

\section{References}

ASABE, 2008. S319.4: Method of determining and expressing fineness of feed materials by sieving. ASABE, Michigan.

ASTM, 2006. ASTM E871-82. Standard test method for moisture analysis of particulate wood fuels. ASTM International, Pennsylvania.

Barbosa-Canovas, G.V., Ortega-Rivas, E., Juliano, P., Yan, H., 2005. Food Powders: Physical Properties, Processing and Functionality. Kluwer Academic Publishers, New York.

Bernhart, M., Fasina, O.O., 2009. Moisture effect on the storage, handling and flow properties of poultry litter. Waste Manag. 29 (4), 1392-1398.

Bitra, V.S.P., Womac, A.R., Cannayen, I., Miu, P.I., Igathinathane, C., Sokhansanj, S., Smith, D.R., 2009. Direct mechanical energy emeasures of hammer mill communication of switchgrass, wheat straw, and corn stover and analysis of their particle size distributions. Powder Technol. 193, 32-45.

Cadoche, L., López, G.D., 1989. Assessment of size reduction as a preliminary step in the production of ethanol from lignocellulosic wastes. Biol. Wastes 30 (2), 153-157.

Cherubini, F., Strømman, A.H., 2011. Life cycle assessment of bioenergy systems: state of the art and future challenges. Bioresour. Technol. 102, 437-451.

Chua, K.J., Mujumdar, A.S., Hawlader, M.N.A., Chou, S.K., Ho, J.C., 2001. Batch drying of banana pieces - effect of stepwise change in drying air temperature on drying kinetics and product colour. Food Res. Int. 34, 721-731.

Colley, Z., Fasina, O., Bransby, D., Lee, Y., 2006. Moisture effect on the physical characteristics of switchgrass pellets. Trans. of the ASABE, 49, 1845-1851.

Crawford, N.C., Ray, A.E., Yancey, N.A., Nagle, N., 2015. Evaluating the pelletization of "pure" and blended lignocellulosic biomass feedstocks. Fuel Process. Technol. 140, 46-56.

Dooley, J.H., Lanning, D.N., Lanning, C.J., 2013. Woody biomass size reduction with selective material orientation. Biofuels 4, 35-43.

Earle, R.L., 1983. Unit operations in food processing, second ed. Elsevier, England.

EPA, 2012. Overview of greenhouse gases. http://www3.epa.gov/climatechange/ghgemissions/gases/co2.html (accessed 10.01.16).

Fasina, O.O., 2008. Physical properties of peanut hull pellets. Bioresour. Technol. 99, 1259-1266.

Fayed, M.E., Skocir, T., 1996. Mechanical Conveyors: Selection and Operation. CRC Press, Florida.

Ghorbani, Z., Masoumi, A. A., Hemmat, A., 2010. Specific energy consumption for reducing the size 
of alfalfa chops using a hammer mill. Biosyst. Eng. 105, 34-40.

Goncalves, B., Till, D., Fasina, O., Tamang, B., Gallagher, T., 2015. Influence of bark on the physical and thermal decomposition properties of short-rotation eucalyptus. Bioenergy Res. 8, 1414-1423.

Havimo, M., Hari, P., 2010. Temperature gradient in wood during grinding. Appl. Math. Model. 34, 2872-2880.

Hehar, G., Fasina, O., Adhikari, S., Fulton, J., 2014. Ignition and volatilization behavior of dust from loblolly pine wood. Fuel Process. Technol. 127, 117-123.

Himmel, M., Tucker, M., Baker, J., Rivard, C., Oh, K. Grohmann, K., 1985. Comminution of biomass: hammer and knife mills. Biotechnol. and Bioeng. Symp. 15, 39-58.

Jenike, A.W., 1964. Storage and flow of solids. University of Utah, Engineering Experiment Station, Utah.

Kaliyan, N., Morey, R.V., 2009. Factors affecting strengtha and durability of densified biomass products. Biomass and Bioenergy 33, 337-359.

Kokko, L., Tolvanen, H., Hämäläinen, K., Raiko, R., 2012. Comparing the energy required for fine grinding torrefied and fast heat treated pine. Biomass and Bioenergy 42, 219-223.

Koyuncu, T., Tosun, İ., Pınar, Y., 2007. Drying characteristics and heat energy requirement of cornelian cherry fruits (Cornus mas L.). J. Food Eng. 78, 735-739.

Lam, P.S., Sokhansanj, S., Bi, X., Lim, C.J., Naimi, L.J., Hoque, M., Mani, S., Womac, A.R., Narayan, S., Ye, X.P., 2008. Bulk density of wet and dry wheat straw and switchgrass particles. Appl. Eng. Agric., 24 (3), 351-358.

Lin, Y., Pan F., 2015. Monitoring woody biomass chips quality change during field storage in Michigan. For. Prod. J. 65, 327-336.

Lu, H., Scott, J., Echols, K., Foster, P., Ripa, B., Farr, R., Baxter, L. L., 2004. Effects of particle shape and size on black liquor and biomass reactivity. http://acerc.byu.edu/News/ICRC/Hongs\%20Paper.pdf (accessed 03.12.15).

. Specific energy requirement for compacting corn stover. Bioresour. Technol. 97, 1420-1426.

Mani, S., Tabil, L.G., Sokhansanj, S., 2004. Grinding performance and physical properties of wheat and barley straws, corn stover and switchgrass. Biomass and Bioenergy 27, 339-352.

Mani, S., Tabil, L.G., Sokhansanj, S., 2006a. Effects of compressive force, particle size and moisture content on mechanical properties of biomass pellets from grasses. Biomass and Bioenergy 30, 648654.

Mani, S., Tabil, L.G., Sokhansanj, S., 2006bMcKendry, P., 2002. Energy production from biomass (part 2): conversion technologies. Bioresour. Technol. 83, 47-54.

Miao, Z., Grift, T. E., Hansen, A. C., Ting, K. C., 2011. Energy requirement for comminution of biomass in relation to particle physical properties. Ind. Crops Prod. 33, 504-513.

Momenikouchaksaraei, M., 2013. Fundamental Study of Single Biomass Particle Combustion. http://vbn.aau.dk/files/80822139/maryam_momeni.pdf (accessed 03.12.15).

Mujundar, A.S., 2003. Drying of biotechnological products: current status and new developments in: Food Science and Food Biotechnology. Gutierrez-Lopez G.F., Barbosa-Canovas, G.V. (eds). CRC 
Press, Florida, pp. 267-277.

Naimi, L. J., Sokhansanj, S., Bi, X., Lim, C.J., Womac, A.R., Lau, A.K., Melin, S., 2013. Development of size reduction equations for calculating energy input for grinding lignocellulosic particles. Appl. Eng. Agric. 29, 93-100.

Naimi, L.J., Collard, F., Bi, X., Lim, C.J., Sokhansanj, S., 2016. Development of size reduction equations for calculating power input for grinding pine wood chips using hammer mill. Biomass Convers. and Biorefinery (in press).

Oyedeji, O., Fasina, O., Adhikari, S., McDonald, T., Taylor, S., 2016. The effect of storage time and moisture content on grindability of loblolly pine (Pinus taeda). Eur. J. of Wood and Wood Products, $1-10$.

Phanphanich, M., Mani, S., 2011. Impact of torrefaction on the grindability and fuel characteristics of forest biomass. Bioresour. Technol. 102, 1246-1253.

Pirasteh, G., Saidur, R., Rahman, S., Rahim, N., 2014. A review on development of solar drying applications. Renew. and Sustain. Energy Rev. 31, 133-148.

Price, M., 2011. Woodchip drying. http://www.biomassenergycentre.org.uk/pls/portal/docs/page/resources/ref_lib_res/publications/tec hnical_development/fcpr045\%20woodchip\%20drying.pdf (accessed 10.05.16).

Probst, K.V., Ambrose, R.P.K., Pinto, R.L., Bali, R., Krishnakumar, P., Ileleji, K.E., 2013. The Effect of Moisture Content on the Grinding Performance of Corn and Corncobs by Hammermilling. Trans. of the ASABE 56, 1025-1033.

Samuelson, L.J., Eberhardt, T.L., Bartkowiak, S.M., Johnsen, K.H., 2013. Relationships between climate, radial growth and wood properties of mature loblolly pine in Hawaii and a northern and southern site in the southeastern United States. For. Ecol. and Manag. 310, 786-795.

SIS, 2006. Standard CEN/TS 15148: Solid biofuels - method for the determination of the content of volatile matter. Swedish Standards Institute, Stockholm, Sweden.

Sluiter, A, Hames, B., Ruiz, R., Scarlata, C., Sluiter, J., Templeton, D., 2008. Determination of ash in biomass by laboratory analytical procedure. http://www.nrel.gov/docs/gen/fy08/42622.pdf (accessed 01.05.15)

Soetaert, W., Vandamme, E.J., 2009. Biofuels in Perspective. in: Soetaert W., Vandamm, E.J. (Ed.), Biofuels. John Wiley and Sons, London, pp. 1-8.

Souček, J., Hanzlikova, I., Hutla, P., 2003. A fine disintegration of plants suitable for composite biofuels production. Res. Agric. Eng. 1, 7-11.

Tabil, L., Sokhansanj, S., 1996. Process conditions affecting the physical quality of alfalfa pellets. Appl. Eng. in Agric., 12, 345-350.

Tabil, L., Adapa, P., Kashaninej, M., 2011. Biomass Feedstock Pre-Processing - Part 1: Pre-Treatment. In: Bernardes M.A. (Eds.), Biofuel's Engineering Process Technology. InTech, Rijeka, Croatia, pp. 411-430.

USDA., 2015. Bioenergy statistics: Overview. http://www.ers.usda.gov/data-products/us-bioenergystatistics.aspx (accessed 03.12.15).

Zhao, D., Kane, M., Teskey, R., Markewitz, D., Greene, D., Borders, B., 2014. Impact of management 
on nutrients, carbon, and energy in aboveground biomass components of mid-rotation loblolly pine (Pinus taeda L.) plantations. Ann. For. Sci. 71, 843-851. 